\title{
Plants for food, energy and sustainability
}

Published online: 16 February 2017 - (C) Società Italiana di Fisica / Springer-Verlag 2017

After a very long hunting-gathering period, the first agricultural civilizations were born at the end of the last ice age in four primary areas of domestication (Fertile Crescent, Far East, Central America and Sub-Saharian region). Agricultural practices generated a surplus of food, which was a prerequisite for developing cities as centres of trade, communication and administration.

During the twentieth century, taking advantage of the vast body of the discoveries of the previous century in the fields of genetics and cultivation techniques, the modern agriculture was developed.

At present, agriculture has become highly mechanized and yields more food than ever before and provides both the basis for supporting our above 7 billion human population on Earth as well as having most of us living in cities. Less than $20 \%$ of our global population works to provide the whole mankind with food. As environmental problems, partly caused by agriculture itself, and resource constraints are arising, we now turn to agriculture in the hope for solutions regarding future sustainability.

Could agriculture provide us with both food and fuel? Could we contribute to climate change mitigation by letting plants help us stabilize the soils, clean and store water and exploit the carbon dioxide that has been accumulated in the atmosphere? There are many promises, and we know that plants are our ultimate companions in life. However, more systemic methods are required to cope with multi-functionality and living systems so that we do not end up causing new problems as we try to cope with those already there. This Focus Point addresses the present and historical development of agriculture, perspectives of plant exploitation for food and energy production as well as for climatic mitigation in a logic of social, economic and environmental sustainability.

Gianluca Alimonti, S. Johansson, and L. Mariani 